\title{
STYLUS PROFILOMETRY IN SURFACE ROUGHNESS MEASUREMENTS OF THE VERTICAL CONICAL MIXING UNIT USED IN A FOOD INDUSTRY
}

\author{
W. Kapłonek ${ }^{1}$, M. Ungureanu ${ }^{2}$, K. Nadolny ${ }^{1 *}$, P. Sutowski ${ }^{1}$ \\ ${ }^{1}$ Department of Production Engineering, Koszalin University of Technology, Koszalin, Poland \\ ${ }^{2}$ Department of Engineering and Technological Management, Technical University of Cluj Napoca, \\ North University Center of Baia Mare, Baia Mare, Romania \\ *Corresponding email: krzysztof.nadolny@tu.koszalin.pl
}

\begin{abstract}
In the paper, use of stylus profilometry technique in measurements of surface roughness parameters of technological equipment used in the food industry has been demonstrated. The assessment of internal surfaces of the vertical conical mixing unit and its components was carried out by the use of stylus instrument Hommel-Tester T-8000 supported by the HommelMap Basic 3.1 software. The obtained values of selected roughness (profile) parameters (Ra, Rq, Rp, Rv and Rz) as well as results of the others carried out analysis (Abbott-Firestone curves, graphical studies of Sk parameters) confirmed the correctness of machining process of the assessed surfaces, despite fact, that measurement process were complicated due to their large size and weight.
\end{abstract}

Keywords: Stylus profilometry, high-accuracy measurements, surface roughness, vertical conical mixing unit

\section{INTRODUCTION}

It's hard to imagine the modern food industry without a wide range types of technological devices (eg. process and storage tanks, reactors, fermenters, mixing units) $)^{1-3}$ that ensure a high quality of products and continuity of their production. The industrial applications of these devices require the fulfillment of many, often quite stringent, requirements concer-ning, appropriate selection of materials ${ }^{4}$ from which they are made and obtaining assumed surface properties ${ }^{5}$. This applies especially to those surfaces that come into direct contact with the manufactured product ${ }^{6}$. Their state, determined by the surface texture, is the subject of constant assessment carried out by a measurement method, which is an adequate and possible to use in the given case.

From many measurement methods used in assessing the surface state of food products, the stylus profilometry $^{7,8}$ plays a dominant role. It is still the most perfect method for measuring surface texture, which given the most complete characteristic of its features. In addition, this technique is characterized by such advantages as ${ }^{7-9}$ :

- a high-accuracy and repeatability of the measurements, allowing for the precise assessment of a full character of analyzed surface (without occurring the unmeasured points);

- a high-density sampling, which allow to obtain the high resolution of the measured data;

- possibility to carried out a $2 \mathrm{D} / 3 \mathrm{D}$ surface measurements and determine a large number of surface texture parameters and functions;

- moderate cost of the instrument, relatively long time of its operation, durable and upgradable.

Despite many of the listed advantages of this measurement technique, its application in the above applications entails some (micro and macro) limitations, resulting from the characteristics and microgeometry of the analyzed surfaces as well as the dimensions of the devices on which these surfaces are located. Measurements of the surface (carried out in industrial conditions), in some cases, requires precision placement of a measuring instrument (often portable with external power supply) inside the assessed device. Such measurement procedure is required e.g. during measurements of roughness of the internal surfaces of tanks. For the devices characterized by smaller size and weight, which does not exceed the load capacity of the granite plate (a base of the profilometer), and are stabilized by means of a set of v-blocks and suitable holders the measurements can be carried out directly by instrument installed on the measuring position. Such above mentioned case was presented in this paper. The detailed description of the surface roughness measurements carried out by stylus pro-filometer for selected components of the vertical conical mixing unit (Section: Experimental studies), was preceded by review regarding the most important issues covered genesis of stylus profile-metry technique, development of stylus instruments, their principle of operation and most important metrological parameters (Section: Literature review). Example results of obtained measurements with its proper interpretation (Section: Results and discu-ssion) as well as a conclusions were given at the final part of the paper.

\section{LITERATURE REVIEW}

In the development of measurement methods for assessment of the state of machined surfaces, from the beginning a two main directions related to mechanical and optical methods were dominated. At the end of the 1920's of the XX century, G. Schmaltz developed the first mechanical device using a stylus ${ }^{10}$. A similar device, called stylus pro-filometer or stylus instrument, was introduced in 1933 by E. J. Abbott ${ }^{11,12}$. For many years, however, it was not broadly used, despite the obtaining a patent (U.S. Patent 2,240,278, British Patent 523436). This situation lasted until 1936, when a few very first instruments were purchased by 
Chrysler (totally a few hundred were made). At the same time, another stylus instrument - surface analyzer was presented by Brush Development Company. However, the instrument was not such accurate and popular as E. J. Abbott profilometer. In Europe, since 1940, the British-based Taylor-Hobson has started the industrial production of the Talysurffamily measuring instruments ${ }^{6}$. Invented name Talysurf means to measure the surface. The word taly comes from Greek $\left(\tau \alpha \lambda_{l}\right)$ and means to measure ${ }^{13}$.

Stylus profilometry turned out to be a major breakthrough that implied the development of the mechanical measurement methods for years to come. The principle of measuring by stylus profile-meter remains unchanged for many years and consists in measuring the profile of the examined surface with a conical-shaped blade with a small radius of rounding the tip $(2,2.5,5 \text { and } 10 \mu \mathrm{m})^{14,15}$ that moves along the surface to be measured. The acquired measurement signal, after the propered gain, was sent to the computer where it could be processed in such a way that the values of the selected parameters and functions of surface roughness were obtained ${ }^{7-9}$.

Over the years, profilometers have been modified and improved with a number of solutions developed by Altimet, Diavite, Hommelwerke, KLATencor, Mahr, Mitutoyo, Taylor-Hobson, Vecco and others. In Poland many innovative solutions in this field were introduced by the Institute of Advanced Manufacturing Technology (pol. Instytut Zaawansowanych Technologii Wytwarzania) - the only domestic manufacturer of stylus profilometers. However, a major breakthrough occurred when modern electronic components (microcontrollers, transducers) were introduced, as well as digital signal processing technique and a broader use of computers. This allowed to obtain a new quality of measurement - realized in 3D, with high accuracy, the results of which could be properly visualized.

The modern stylus profilometers have a wide range of resolutions, depending on the purpose of the instrument. Typical vertical magnification ranges from $200 \times$ to $100,000 \times$, whereas horizontal up to $2000 \times$. In instruments characterized by a highest accuracy of measurements, vertical magnifications reach even a several million times at a vertical resolution of less than $1 \mathrm{~nm}$, while horizontal magnifications typically do not exceed $50000 \times$ at horizontal resolution up to tens of nanometers ${ }^{7-9}$.

One of the recent trend in the construction of profilometers is solution proposed by the Altimet, in the form probe using a diamond blade with low contact force $0.01 \mathrm{mN}$ (standard 0.6 to $2.0 \mathrm{mN}$ ). The development of this type of probe made it possible to solve one of the most important problems occurring in a stylus technique. This problem was related with potential to scratch or damage surfaces, especially smooth and supersmooth surfaces ${ }^{16}$ (eg. high-accuracy optical elements, opto- electronic components, HDD platters and silicon substrates of semiconductors) and less resistant to debris, susceptible to deformation and sensitive to physical or chemical impacts. Precise assessment of surfaces, including surfaces of devices used in food industry, is carried out using a stylus profilometry. Unless other measurement techniques are required, due to the specific nature or characteristics of the surface, this method is usually used as a first, while the sub-sequent methods (eg. optical profilometry, confocal laser microscopy) are treated as additional ${ }^{17}$.

\section{EXPERIMENTAL STUDIES}

\section{Main goal of the experimental studies}

The main goal of carried out experiments was assessment of selected surfaces of measured vertical conical mixing unit and its elements in terms of their surface texture (analysed by the roughness parameters and functions). An additional goal was analysing possibilities of use stylus profilometry in assessment of a such surfaces for device, which is relatively hard to measure (due to the size).

\section{Characteristic of vertical conical mixing unit}

The main purpose of use the mixing unit in a food industry is mix, heat and cool of wide range of products. Typical construction of the mixing unit consist a tank of the shape of a vertical cylinder, which tapering downwards and forming a conical shape. At the top of the mixer comprises a lid with holes for mounting the stirrer with the motor-reducer assembly. Depending on given industrial application, the mixing unit may also include additional components, such as insulation, level indicator, connecting pipes, instrumentation, side and upper manholes and service ladders. The construction is often situated on legs finished with threaded stainless steel ends allowing for precise adjusting the height of the mixing unit.

Used in experiments mixing unit made from stainless steel $316 \mathrm{~L}$ is presented in a Fig. 1a, whereas characteristic of its material in Tab. 1.

\section{Stylus measurements}

During experimental studies a stylus profilometer Hommel-Tester T8000 (Hommelwerke GmbH, Villingen-Schwenningen, Germany) $)^{18,19}$, presented in general view in Fig.1b, were used. The instrument was equipped with a TKL 100 pick-up with a diamond stylus tip (tip radius: $2.5 \mu \mathrm{m}$ ). The measuring element was a part of traverse unit Waveline ${ }^{\mathrm{TM}} 60$ Basic (tracing length: $60 \mathrm{~mm}$, resolution: $0.1 \mu \mathrm{m}$, tracing speed: $0.1-3 \mathrm{~mm} / \mathrm{s}$ ) mounted on a measuring column Wavelift ${ }^{\mathrm{TM}} 400 \mathrm{M}$ (max. traverse: $400 \mathrm{~mm}$ ). The column was, in turn, mounted on a granite plate Wavesystem $^{\mathrm{TM}} 780(780 \times 500 \times 100 \mathrm{~mm})$. On the plate a set of v-blocks was placed as a platform for 
Table 1. Chemical composition and selected physical/mechanical properties of stainless steel $316 \mathrm{~L}$

\begin{tabular}{|c|c|c|c|c|c|c|c|c|}
\hline \multirow{2}{*}{ Element } & \multicolumn{2}{|c|}{ Percentage, $\%$} & \multicolumn{3}{|c|}{ Physical properties } & \multicolumn{3}{|c|}{ Mechanical properties } \\
\hline & Min. & Max. & Feature & Value & Unit & Feature & Value & Unit \\
\hline $\mathrm{C}$ & - & 0.035 & \multirow{2}{*}{$\begin{array}{l}\text { Specific heat } \\
\left(0-100^{\circ} \mathrm{C}\right)\end{array}$} & \multirow{2}{*}{500} & \multirow{2}{*}{$\mathrm{J} \cdot \mathrm{kg}^{-1} \cdot{ }^{\circ} \mathrm{K}^{-1}$} & \multirow{2}{*}{ Tensile strength } & \multirow{2}{*}{485} & \multirow{2}{*}{$\mathrm{MPa}$} \\
\hline $\mathrm{Mn}$ & - & 2.00 & & & & & & \\
\hline $\mathrm{P}$ & - & 0.045 & \multirow[b]{2}{*}{ Thermal conductivity } & $16.3^{*}$ & \multirow{2}{*}{$\mathrm{W} \cdot \mathrm{m}^{-1} \cdot{ }^{\circ} \mathrm{K}^{-1}$} & \multirow{2}{*}{ Yield strength } & \multirow{2}{*}{170} & \multirow{2}{*}{$\mathrm{MPa}$} \\
\hline $\mathrm{S}$ & - & 0.03 & & $21.4^{* *}$ & & & & \\
\hline $\mathrm{Si}$ & - & 1.00 & \multirow{2}{*}{ Thermal expansion } & \multirow{2}{*}{15.9} & \multirow{2}{*}{$\mathrm{mm} / \mathrm{m} /{ }^{\circ} \mathrm{C}$} & \multirow{2}{*}{ Elongation } & \multirow{2}{*}{40} & \multirow{2}{*}{$\begin{array}{c}\% \text { in } \\
50 \mathrm{~mm}\end{array}$} \\
\hline $\mathrm{Cr}$ & 16.00 & 18.00 & & & & & & \\
\hline $\mathrm{Ni}$ & 10.00 & 15.00 & \multirow{2}{*}{ Modulus elasticity } & $193^{* * *}$ & \multirow{2}{*}{$\mathrm{GPa}$} & \multirow{2}{*}{ Hardness } & \multirow{4}{*}{95} & \multirow{4}{*}{-} \\
\hline Mo & 2.00 & 3.00 & & $77^{* * * *}$ & & & & \\
\hline $\mathrm{N}$ & - & 0.10 & \multirow{2}{*}{ Electrical resistivity } & \multirow{2}{*}{7.4} & \multirow{2}{*}{$\mu \Omega / \mathrm{cm}$} & \multirow{2}{*}{$\begin{array}{l}\text { Rockwell B } \\
\text { (HR B) }\end{array}$} & & \\
\hline $\mathrm{Fe}$ & \multicolumn{2}{|c|}{ Balance } & & & & & & \\
\hline & & & Density & 7.99 & $\mathrm{~g} / \mathrm{cm}^{3}$ & $\begin{array}{l}\text { Brinell } \\
(\mathrm{HB})\end{array}$ & 201 & - \\
\hline
\end{tabular}

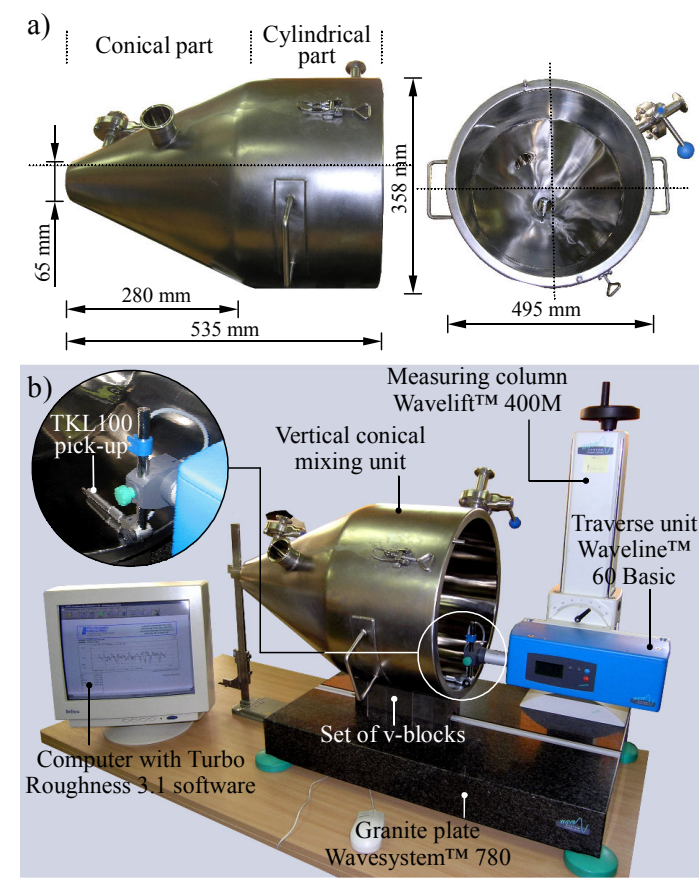

Figure 1. Vertical conical mixing unit used in experimental studies: a) general view of the device and its characteristically dimensions; b) measuring stand equipped with stylus profilometer HommelTester T8000 during internal surface roughness assessment of the device

mounting the vertical conical mixing unit. Due from the size of the device all assembly and measurement operations were done very carefully, so as not to damage a measuring unit of the profilometer. For setting conditions and carried out the measurements stylus profilometer used a dedicated Turbo Roughness 3.1 software provided by producer of the instrument, while for processing of measurement data, calculating the roughness parameters, various surface analysis and visualization - HommelMap Basic 3.1 software using
Mountains Technology ${ }^{\mathrm{TM}}$ (Digital Surf, Besançon, France).

Measurements were made at ten randomly selected areas on cylindrical and conical part of the device. Additionally the same number of measurements on top cover and elements of vertical mixer shaft and one of the propeller blade were carried out. The measuring settings of the instrument for selected surfaces were given in Figs. 2-4.

\section{RESULTS AND DISCUSSION}

In this section selected results of measurements were presented in a form of a set which including:

- a general view of device and its elements on measuring stand during assessment;

- profiles of roughness of a two example areas;

- calculated values of surface texture parameters;

- Abbott-Firestone curves;

- graphical studies of $R k$ parameters.

In experimental studies, selected surface texture parameters from a group of roughness (profile) and functional were used. The characteristic of those parameters is given in Tab. 2. Obtained values of above parameters were supported by additional analysis: Abbott-Firestone curves and graphical studies of $S k$ parameters. The first of the listed above analysis, known also as material ratio curve or bearing area curve, was proposed by E. J. Abbott and F. A. Firestone in $1933^{12}$. The curve describe the ratio between relative amount of surface (abscissa) above a given height level (ordinate) for profile and is divided for three parts: projection, central exploitation and low depression. From math-ematical point of view is the cumulative probability density function of the surface profile height. On basis of Abbott-Firestone curve the $R k$ family parameters were determined.

Listed above sets of measurements for various areas of conical and cylindrical part of the mixing unit as well as its top cover are presented in Figs. 2-4, while values of roughness (profile) parameters 

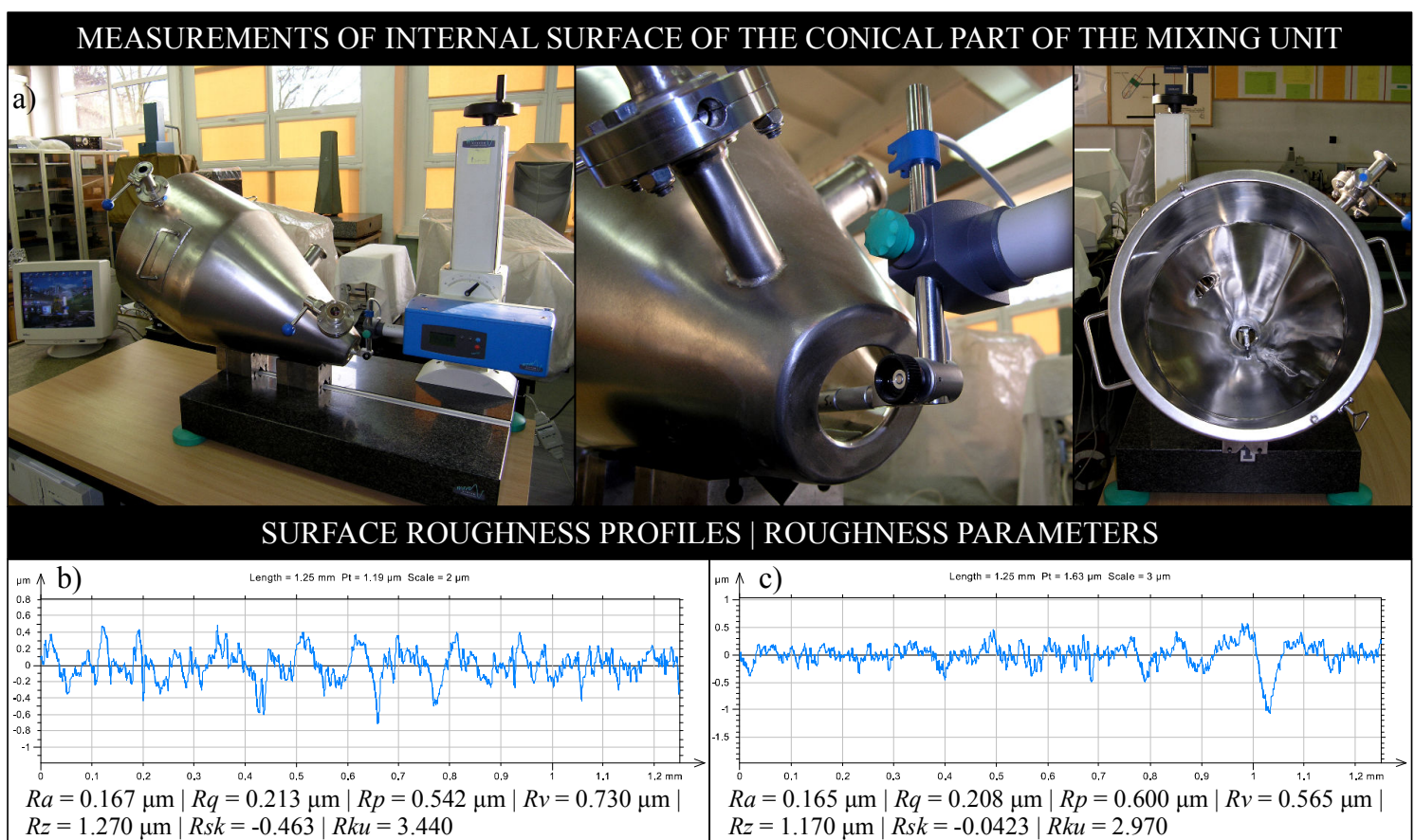

ABBOTT-FIRESTONE CURVES | GRAPHICAL STUDIES OF Rk PARAMETERS
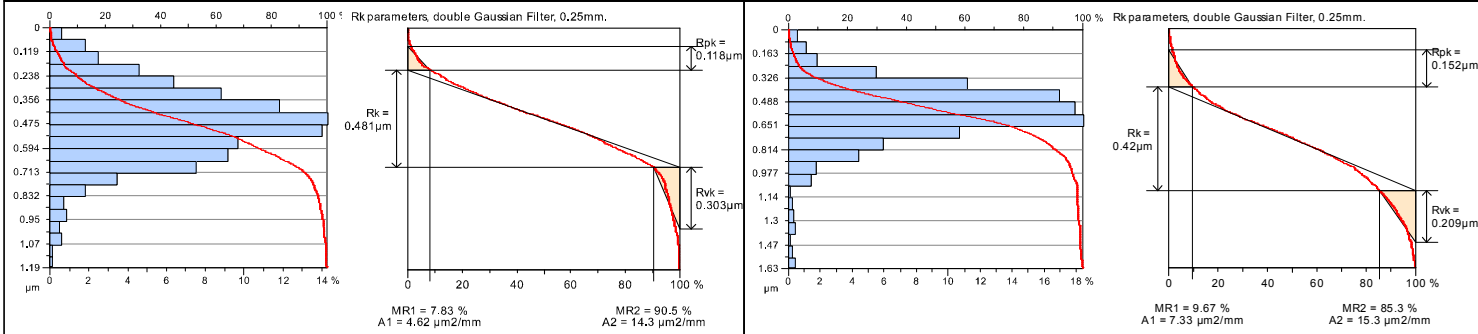

\section{MEASUREMENT CONDITIONS}

Instrument: stylus profilometer | Type: Hommel-Tester T8000 | Producer: Hommelwerke GmBH | Measurement settings: Turbo Roughness 3.1 software | Measurement data processing: HommelMap Basic 3.1 | Measuring length: $1.5 \mathrm{~mm} \mid$ Number of surface roughness profiles: 1 Number of profile points: 3971 | Distance between points of the profile: $0.378 \mu \mathrm{m} \mid$ Measuring time: $\sim 10 \mathrm{~s}$.

Figure 2. Selection of results from experimental studies carried out for the conical part of the vertical conical mixing unit by stylus profilometer Hommel-Tester T8000: a) general view of the device during measurements; b) results obtained for Area 3; c) results obtained for Area 8

Table 2. Selected parameters calculated for measured surfaces during experimental studies

\begin{tabular}{l|l|c|c|}
\hline Group of parameters & \multicolumn{1}{|c|}{ Parameter } & Designation & Unit \\
\hline \multirow{4}{*}{$\begin{array}{l}\text { Roughness (profile) } \\
\text { parameters }\end{array}$} & Arithmetical mean deviation of the roughness profile & $R a$ & $\mu \mathrm{m}$ \\
\cline { 2 - 4 } & Root mean square deviation of the roughness profile & $R q$ & $\mu \mathrm{m}$ \\
\cline { 2 - 4 } & Maximum profile peak height within a sampling length & $R p$ & $\mu \mathrm{m}$ \\
\cline { 2 - 4 } & Maximum profile valley depth within a sampling length & $R v$ & $\mu \mathrm{m}$ \\
\cline { 2 - 4 } & Maximum height of the profile within a sampling length & $R z$ & $\mu \mathrm{m}$ \\
\cline { 2 - 4 } & Skewness (asymmetry) of the assessed profile & $R s k$ & - \\
\cline { 2 - 4 } & Kurtosis of the assessed profile & $R k u$ & - \\
\hline \multirow{4}{*}{$\begin{array}{l}\text { Functional parameters } \\
\text { (bearing ratio } \\
\text { parameters) }\end{array}$} & Kernel roughness depth (roughness depth of the core) & $R k$ & $\mu \mathrm{m}$ \\
\cline { 2 - 4 } & Reduced valley depth (roughness depth of the valleys) & $R v k$ & $\mu \mathrm{m}$ \\
\cline { 2 - 4 } & Upper material ratio & MR1 & $\%$ \\
\cline { 2 - 4 } & Lower material ratio & MR2 & $\%$ \\
\cline { 2 - 4 } & Upper area (area of the triangle equivalent to the peaks) & $\mathrm{A} 1$ & $\mu \mathrm{m}^{2} / \mathrm{mm}$ \\
\cline { 2 - 4 } & Lower area (area of the triangle equivalent to the holes) & $\mathrm{A} 2$ & $\mu \mathrm{m}^{2} / \mathrm{mm}$ \\
\hline
\end{tabular}

${ }^{*}$ Parameters included in ISO $4287^{20}$ standard, ${ }^{* *}$ Parameters included in ISO $13565-2^{21}$ standard 


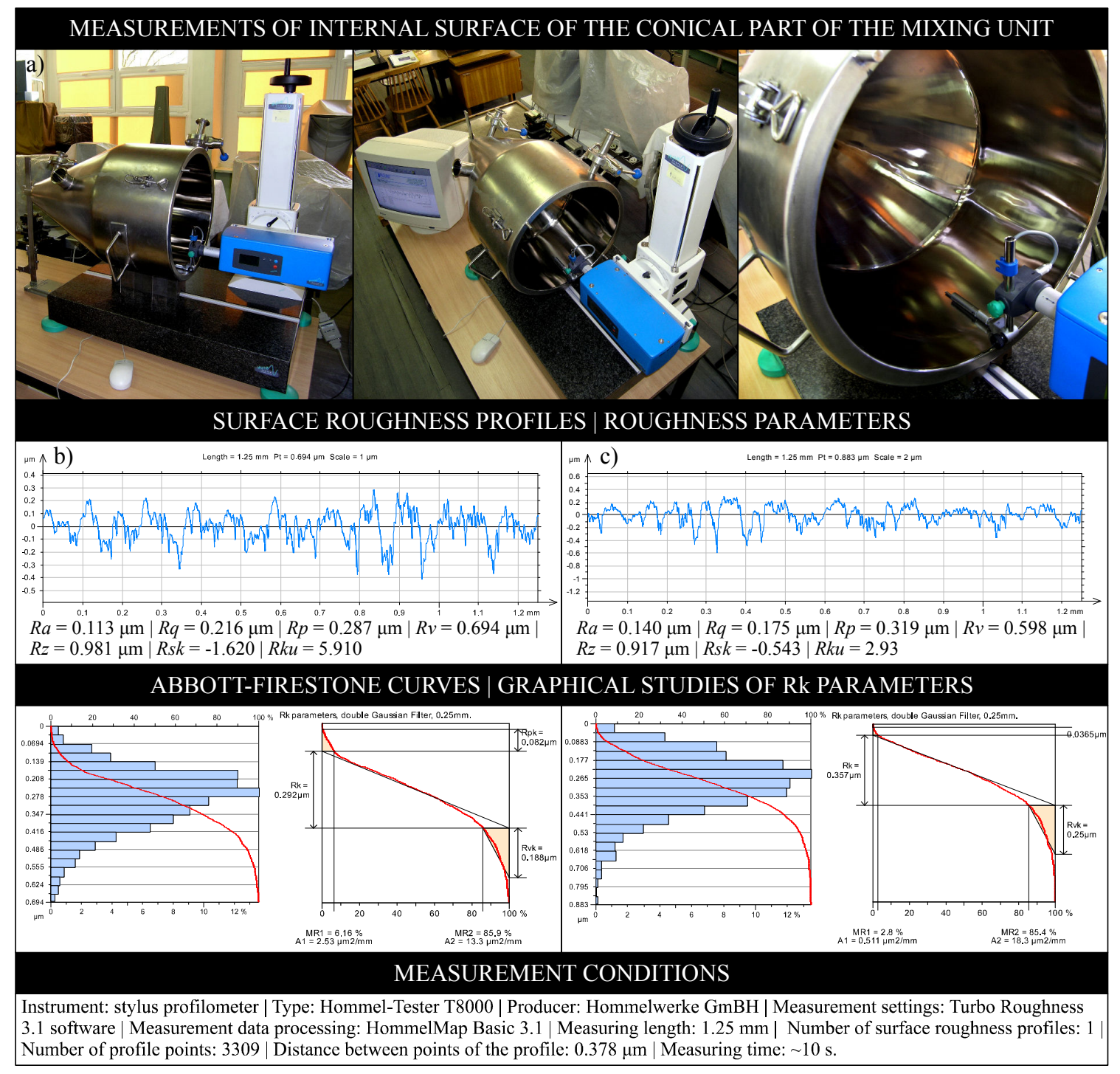

Figure 3. Selection of results from experimental studies carried out for the cylindrical part of the vertical conical mixing unit by stylus profilometer Hommel-Tester T8000: a) general view of the device during measurements; b) results obtained for Area 2; c) results obtained for Area 4

are given in Fig. 5. The analysis of presented results allows to conclude that the values distributions of Abbott-Firestone curves were generally similar for all surfaces of the device. It's means that the machining process were correctly carried out. The values obtained for conical part of the device were in the range from 0.120 to $1.655 \mu \mathrm{m}$, while values for cylindrical part and top cover - from 0.050 to 0.850 $\mu \mathrm{m}$ (lower on average $50 \%$ ). A similar trend was also observed for values of $R k$ family parameters. The values determined for conical part of the device were on average $\sim 27-41 \%(R k), \sim 27-42 \%(R p k), \sim 24-28 \%$ $(R v k)$ higher, than for other surfaces. Above mentioned analysis were corresponded with calculated values of roughness parameters prese-nted in Fig. 5 in a form of bar charts. Parameters calculated for conical and cylindrical part of the device were very similar, generally in a range from $>0.100$ to $>1.170 \mu \mathrm{m}$. The $R z$ for cylindrical part of the device, were $\sim 29 \%$ higher than for conical part (and top cover), which was definitely a different value than those measured earlier. Obtained values of all analyzed parameters for internal surfaces of the device were $\sim 20-50 \%$ lower, than values calculated for its top cover. The skewness parameter for these surfaces $R s k<0$, what means that values growing upward relative to the average line, while the kurtosis parameter $R k u>3$, what means that height distribution is sharp.

During experimental studies, the stylus measurements were also carried out for surfaces of additional elements of the device. Obtained values of roughness 

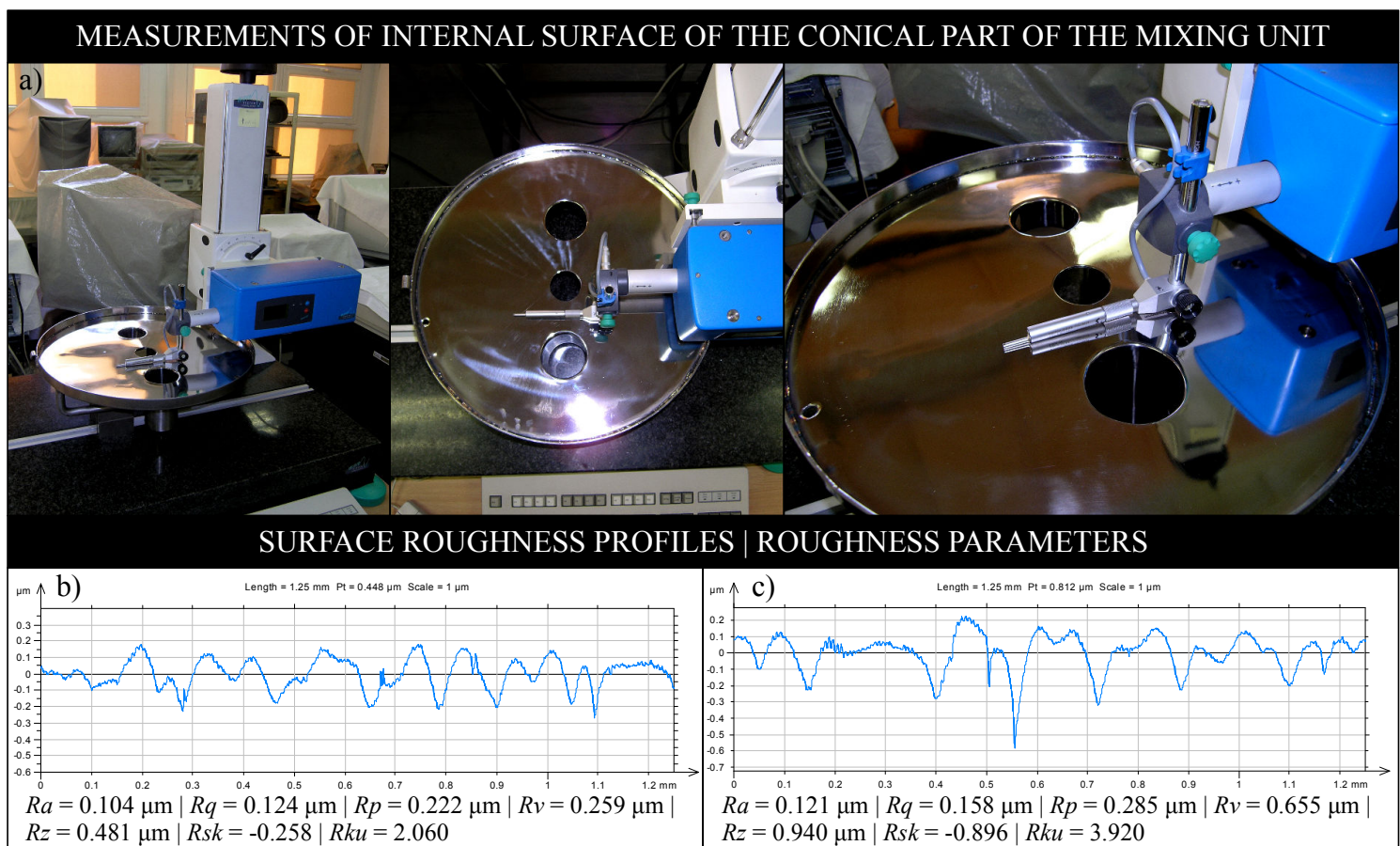

\section{ABBOTT-FIRESTONE CURVES | GRAPHICAL STUDIES OF Rk PARAMETERS}
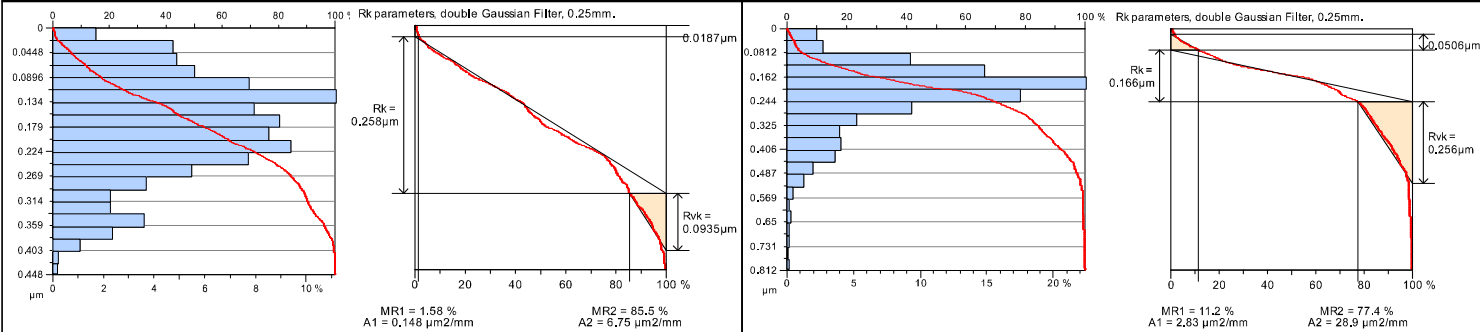

MEASUREMENT CONDITIONS

Instrument: stylus profilometer | Type: Hommel-Tester T8000 | Producer: Hommelwerke GmBH | Measurement settings: Turbo Roughness

3.1 software | Measurement data processing: HommelMap Basic 3.1 | Measuring length: $1.25 \mathrm{~mm}$ | Number of surface roughness profiles: 1 Number of profile points: 3309 | Distance between points of the profile: $0.378 \mu \mathrm{m} \mid$ Measuring time: $\sim 10 \mathrm{~s}$.

Figure 4. Selection of results from experimental studies carried out for the top cover of the vertical conical mixing unit by stylus profilometer Hommel-Tester T8000: a) general view of the device during measurements; b) results obtained for Area 1; c) results obtained for Area 7

(profile) parameters for shaft and propeller blade of the vertical mixer are presented in Fig. 5d-e. These values were in a range from $>0.035$ to $>0.430 \mu \mathrm{m}$ (a $\sim 3$ times lower than for analysed surfaces of the device and top cover). As a general summary for those phase of experimental studies it can be concluded that for the main device and its top cover obtained a surface, which was characterize by higher values of the surface irregularities (tenths of a micrometer), than for surfaces of vertical mixer (hundredths of a micrometer). The values in each of the discussed case were correlated with customer assumption specify in Tab. 3. Although the $R a$ parameter is currently insignificant (mainly from the scientific research point of view), so in general engineering practice is still commonly used. Hence in the table shows the compatibility of obtained results expressed in values of this parameter. Analysis of those values allows to conclude that the surfaces of the main device and its top cover were machined on excellent level. The level of machining process obtained for parts of vertical mixer was mixed, from good (shaft) to acceptable (propeller blade). It is worth pointing out that the results obtained for all measured surfaces, expressed by the parameter $R a$, were less than $0.8 \mu \mathrm{m}$. Such value is recommended among others by European Hygienic Engineering and Design Group as well as American Meat Institute Equipment Design Task Force (currently North American Meat Institute) ) $^{6,22,23}$ for all of those surfaces, which come into direct contact with the manufactured product (in this case food). 
a)

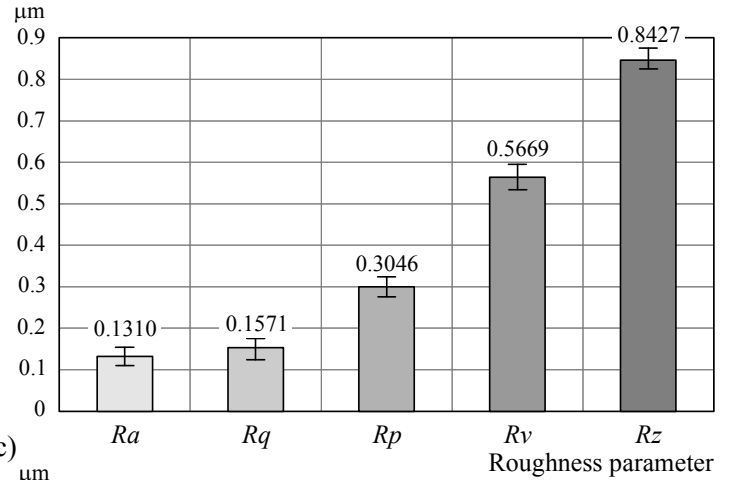

c)
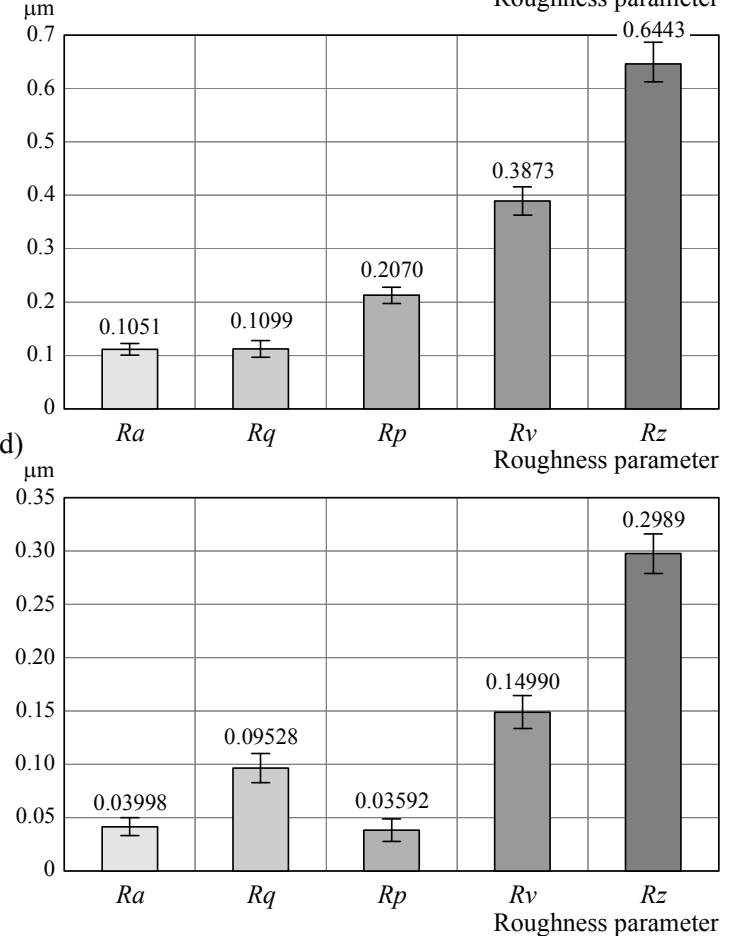

b)

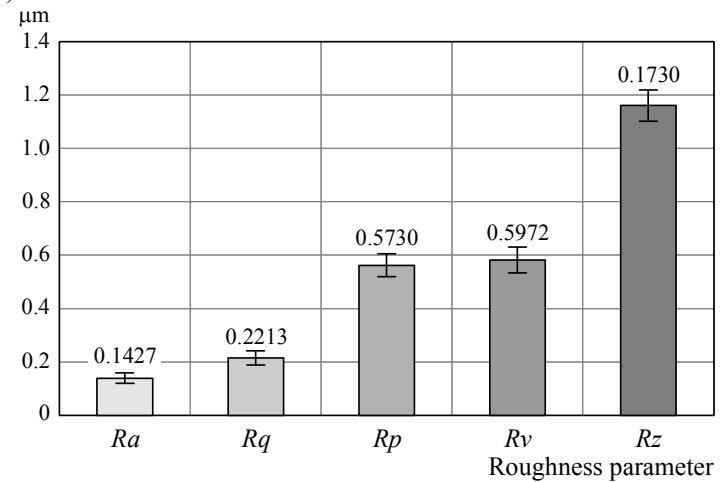

e)

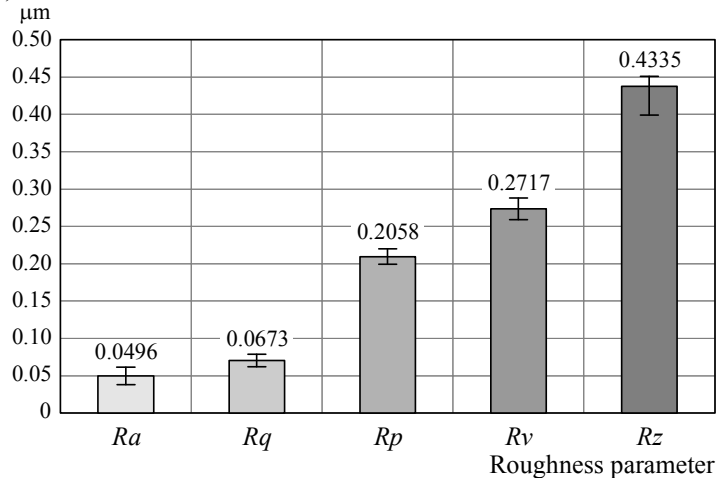

Figure 5. Values of selected roughness parameters ( $R a, R q, R p, R v$ and $R z$ ) measured during experimental studies by stylus profilometer Hommel-Tester T8000 for: a) internal surface of the conical part of the mixing unit; b) internal surface of the cylindrical part of the mixing unit; c) surface of the top cover; d) shaft of the vertical mixer; e) propeller blade of the vertical mixer

Table 3. Comparison of measured values of $R a$ parameter by stylus profilometer Hommel-Tester T-8000 with customer requirements in terms of surface roughness of selected elements the device

\begin{tabular}{llccc}
\hline \multirow{2}{*}{ Element } & \multicolumn{1}{c}{ Surface } & \multicolumn{3}{c}{ Roughness $R a, \mu \mathrm{m}$} \\
\cline { 2 - 5 } & & Measured & Customer requirements & Compatibility \\
\hline \multirow{2}{*}{$\begin{array}{l}\text { Vertical conical } \\
\text { mixing unit }\end{array}$} & Internal surface of the conical part & 0.131 & $0.1-0.8$ & $\cdots$ \\
\cline { 2 - 5 } & Internal surface of the cylindrical part & 0.142 & $0.1-0.8$ & $\cdots$ \\
\hline Top cover & Internal surface & 0.106 & $0.1-0.8$ & $\cdots$ \\
\hline \multirow{2}{*}{ Vertical mixer } & Surface of the shaft & 0.038 & $0.01-0.05$ & $\cdots$ \\
\cline { 2 - 5 } & Surface of the blade & 0.049 & $0.01-0.05$ & $\bullet$ \\
\hline
\end{tabular}

$\bullet \bullet-$ Excellent, $\bullet-$ Good, $\bullet-$ Acceptable

Journal of Mechanical Engineering, Vol. ME 47, December 2017

Transaction of the the Mechanical Engineering Division, The Institution of Engineers, Bangladesh 


\section{CONCLUSIONS}

On the basis of the results of experimental studies carried out on internal surfaces of the vertical conical mixing unit and its components, the following detailed conclusions can be drawn:

- surface of main device was characterized by a small heights of surface irregularities $(R a)$ ranged from 0.131 to $0.142 \mu \mathrm{m}$. A similar value $(0.106 \mu \mathrm{m})$ was obtained for the surface of the top cover. Additional measured elements of vertical mixing (shaft and propeller blade) were characterized by much lower heights of surface irregularities in a range from 0.038 to $0.049 \mu \mathrm{m}$. All obtained values indicate the correct machining process and are accordance with the customer assumptions (Tab. 3);

- stylus profilometry is an adequate technique that allows to carried out an accurate measurements of surface roughness, even when the relatively large size device is assessed;

- support of the instrument with a proper software increases the ability to analysis the assessed surfaces in terms of its various parameters and functions (Tab. 2., Figs. 2-4);

\section{ACKNOWLEDGEMENTS}

The authors wish to thank Mr. Krzysztof Maciejewski from the Laboratory of Metrology and Measurement Systems (Faculty of Mechanical Engineering, Koszalin University of Technology, Koszalin, Poland) for help in surface roughness measure-ments carried out by stylus instrument.

\section{REFERENCES}

1. Troller, J. A., 2012, Sanitation in Food Processing, Academic Press, New York.

2. Soccol, C. R., Pandey, A. and Larroche, C., 2013, Fermentation Processes Engineering in the Food Industry, CRC Press, Boca Raton.

3. Cullen, P. J. (Ed.), 2009, Food Mixing: Principles and Applications, John Wiley and Sons, Chichester.

4. Schmidt, R. H., Erickson, D. J., Sims, S. and Wolff, P., 2012, "Characteristics of food contact surface materials: Stainless steel, "Food Protection Trends, 32(10), 574-584.

5. Jullien, C., Bénézech, T., Carpentier, B., Lebret, V. and Faille, C., 2003, "Identification of Surface Characteristics Relevant to the Hygienic Status of Stainless Steel for the Food Industry," Journal of Food Engineering, 56(1), pp. 77-87.

6. Milledge, J. J., 2010, "The cleanability of Stainless Steel used as a Food Contact Surface: An Updated Short Review," Food Science and Technology Journal, 24(4), pp. 27-28.

7. Whitehouse, D. J., 2010, Handbook of Surface and Nanometrology (2nd Ed.), CRC Press, Boca Raton.

8. Czichos, H., Saito T. and Smith L.E., 2011, Handbook of Metrology and Testing. Springer, Berlin and Heidelberg.
9. Leach, R. K., 2001, Measurement Good Practice Guide No. 37: The Measurement of Surface Texture using Stylus Instruments, National Physical Laboratory, Teddington.

10. Reason, R. E, Garrod, R. I., Hopkins, M. R., 1944, Report on the Measurement of Surface Finish by Stylus Methods, Rank Taylor Hobson, Leicester. 11. Abbott, E. J., Bousky, S., Williamson, D. E., 1938, "The Profilometer," Mechanical Engineering, 60, pp. 205-216.

12. Abbott, E. J, Firestone, F. A., 1933, "Specifying surface quality: a method based on accurate measurement and comparison," Mechanical Engineering, 55, pp. 569-572.

13. Whitehouse, D. J., 2010, Handbook of Surface and Nanometrology, CRC Press, Boca Raton.

14. Lee, D. H. and Cho, N. G., 2012, "Assessment of Surface Profile Data Acquired by a Stylus Profilometer," Measurement Science and Technology, 23(10), 105601 (12 pp.)

15. Smith, G. T., 2002, Industrial Metrology: Surfaces and Roundness. Springer, London.

16. Garratt, J., and Mills, M. ,1996, "Measurement of the Roughness of Supersmooth Surfaces using a Stylus Instrument," Nanotechnology, 7(1), p. 13.

17. Piska, M. and Metelkova J., 2014, "On the Comparison of Contact and Non-contact Evaluations of a Machined Surface," MM Science Journal, 6, pp. 476-480.

18. Nadolny, K., Kapłonek, W., 2014, "Analysis of Flatness Deviations for Austenitic Stainless Steel Workpieces after Efficient Surface Machining," Measurement Science Review, 14(4), 204-212.

19. Kapłonek W., Nadolny K., Ungureanu N., 2016, "Shaping the Surface Texture of the Ring-type Test Samples used for Evaluation of the Surface Roughness by ARS Method based on Imaging and Analysis of the Scattered Light," International Journal of Precision Technology, Vol. 6(2), 101-122.

20. ISO 4287, 1997, Geometrical Product Specifications (GPS) - Surface Texture: Profile Method: Terms, Definitions and Surface Texture Parameters, International Organization for Standardization, Geneva.

21. ISO 13565-2, 1996, Geometrical Product Specifications (GPS) -- Surface texture: Profile method; Surfaces having stratified functional properties -Part 2: Height characterization using the linear material ratio curve, International Organization for Standardization, Geneva.

22. Gerhards, C. and Schmid, A., 2013, “Assessing the cleanability of stainless steel surfaces-development of a testing method for starch and protein based soils," Journal of Hygienic Engineering and Design, 3, pp. 9-14.

23. Schmidt, R. H., Erickson, D. J., Sims, S. and Wolff, P., 2012, "Characteristics of Food Contact Surface Materials: Stainless steel," Food Protection Trends, 32(10), pp. 574-584. 